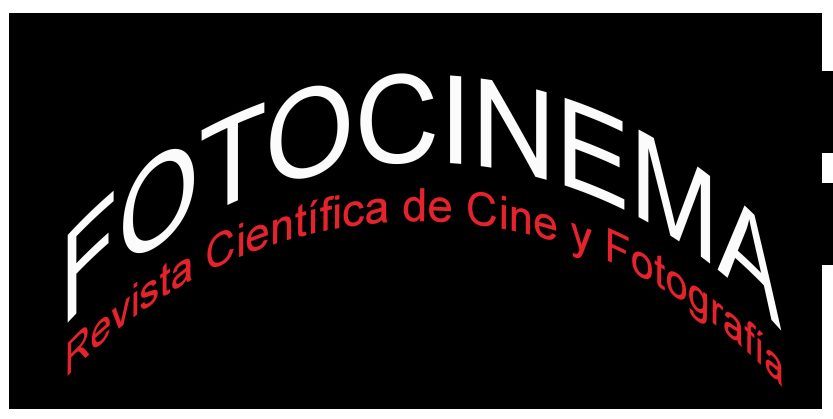

\title{
TIEMPO Y NARRATIVIDAD EN LA FOTOGRAFÍA: DE LA PARADOJA AL CAMPO EXPANDIDO
}

\section{TIME AND NARRATIVITY IN PHOTOGRAPHY: FROM PARADOX TO EXPANDED FIELD}

\author{
Enric Mira Pastor \\ Universidad de Alicante, España \\ enric.mira@ua.es
}

\section{Resumen:}

El análisis de las relaciones entre tiempo y narratividad en la fotografía toma como punto de partida la paradoja entre instantánea y posado, tal como ha sido planteada por Thierry de Duve. De modo correlativo las nociones de estasis y narratividad se relacionan con los términos de la paradoja a partir del tiempo fenomenológico de la experiencia perceptiva y de las cualidades estéticas inherentes a la imagen fotográfica. Sin embargo, el paradigma formalista en el que se enmarca dicho análisis restringe las posibilidades narrativas de la fotografía. Los debates posmodernos en torno a la fotografía que tuvieron lugar en las dos últimas décadas del siglo XX enfocaron una nueva perspectiva para la comprensión narrativa del la imagen sobre la base de la intermedialidad. En este contexto, el concepto de campo expandido de la fotografía se propone como clave conceptual que incorpora, a los anteriores procesos de hibridación medial, las relaciones de la fotografía con el cine así como el impacto de lo digital sobre lo fotográfico para dar cabida a una comprensión cinemática de la fotografía.

\begin{abstract}
:
The analysis of the relationship between time and narrativity in photography takes as point of departure the photographic paradox between snapshot and time exposure, as it has been raised by Thierry de Duve. Notions of stasis and narrativity are related to the terms of the paradox from the phenomenological time of perceptual experience and the aesthetic qualities inherent in the photographic image. However, the formalist paradigm that is part of this analysis restricts the narrative possibilities of photography. Postmodern debates around photography that took place in the last two dacadas of the 2oth century focused a new perspective for understanding narrative of the image based on the intermediality. In this context, the concept of expanded field of photography is proposed as a conceptual key that incorporates previous medial hybridization processes, relations of photography with film as well as the impact of digital on the photographic to accommodate a cinematic photography understanding.
\end{abstract}

Palabras clave:

Fotografía; paradoja; estasis; narratividad; tiempo.

Keywords:

Photography; Paradox; Stasis; Narrativity; Time. 


\section{La paradoja de la fotografía: entre la estasis y la diégesis}

Casi al final de La cámara lúcida, Roland Barthes relativiza algunas de su propias argumentaciones semiológicas en torno a la fotografía para poner de manfiesto, desde una personal aproximación fenomenológica, que lo verdaderamente importante no está en dirimir el carácter analógico o codificado de la imagen fotográfica ${ }^{1}$ sino en su "fuerza constativa" del tiempo, que es más profunda y verdadera que su capacidad para testimoniar la realidad mediante la representación (Barthes, 1990, p. 154-155)². La fotografía está hecha de tiempo, lo que en ella percibimos es el rostro del tiempo, la naturaleza inherente de lo fotográfico, en suma, es de carácter temporal. Sin embargo, como ha mostrado Thierry de Duve en "El posado y la instantánea. La paradoja fotográfica" (2013)3, esta esencia es en sí misma paradójica al entrelazar dos temporalidades heterogéneas entre sí que, a su vez, dan lugar a dos maneras excluyentes -pero sucesivas- de aprehender las imágenes fotográficas. De un lado, tenemos el caso paradigmático del retrato funerario que Thierry de Duve categoriza como "posado" (time exposure). Son fotografías en las que percibimos un tiempo mantenido o sostenido que en la realidad designaría un tiempo pretérito, ya muerto e inmóvil. El ahora que representa el posado es un tiempo "flotando sin anclaje espacial" -en cierto modo irreal- que en la serie referencial remite a un tiempo pasado, y por tanto ausente, que se comporta a modo de un allí, de un espacio o lugar inhabitado (De Duve, 2013, p. 70). Del otro, encontramos como ejemplo la fotografía de reportaje o "instantánea" (snapshot), una imagen que se percibe como la captura de un tiempo detenido, congelado, mientras que a

\footnotetext{
${ }^{1}$ Recordemos que el Roland Barthes semiólogo había apuntado una paradoja estructural en la conformación del significado fotográfico al señalar que el mensaje connotado o codificado se desarrolla a partir de un mensaje denotado que es un "mensaje sin código" (Barthes, 1995a y 1995b).

$2 \mathrm{El}$ tiempo constituye el otro punctum de la fotografía que no emana de un detalle revelador presente en la imagen, sino de la intensidad con la que él mismo se representa como noema de la fotografía (Barthes, 1990, p. 164-165). Aquí aparece el tema de la muerte como co-sustantivo del tiempo.

3 Este artículo fue escrito en 1974 y publicado por primera vez en inglés en October $\mathrm{n}^{\circ} 5$ (1978), número especial dedicado a la fotografía en el que sus editoras, Rosalind Krauss y Annette Michelson, editorializaban sobre la necesidad de elaborar un pensamiento teórico de la fotografía y la contribución que a dicho propósito representaban los contenidos de este número de la revista. El autor amplió el texto para la edición de su libro recopilatorio Essais datés 19741986 (1987). Una posterior revisión de 2005 es la que ha servido, por mediación del propio autor, para la traducción al español en Concreta. Sobre creación y teoría de la imagen, $\mathrm{n}^{\mathrm{0}} 2$ (2013).
} 
nivel referencial el tiempo fluye sin obstrucción. Tal como se comprueba por ejemplo en la cronofotografía de Muybridge, el movimiento es un suceso único que queda demostrado -como concepto- pero no mostrado -como algo vivo-. El movimiento nunca acaba de ser efectuado, resta como en un aquí inhabitable, en tanto que en la realidad el galope es un suceso vivo y contínuo que, en relación al registro fotográfico, ya ha sucedido antes. El posado y la instantánea conforman así dos modelos heurísticos que cifran los componentes de la paradoja de la fotografía a modo de quiasmo: una especie de "reciprocidad asimétrica" cruzada entre lo que ocurre a nivel del signo o de la represtanción fotográfica y lo que acontece en el referente de la realidad: entre el aquí-antes de la intantánea y el ahora-allí del posado (De Duve, 2013, pp. 65-69).

Esta paradoja ontológica es traducida por Thierry de Duve a términos semánticos -epistemológicos, podríamos decir- como tensión entre narratividad y estasis. Para el pensador belga, en la instantánea no hay duración, sólo permanece la estasis residual de un movimiento no efectuado. En esencia la instantánea es traumática por su condición de corte radical de la continuidad, y ante ella "la palabra se queda estupefacta". Desde el punto de vista plástico, el tiempo petrificado de la instantánea se expresa en un aquí puntual que se halla representado visualmente con nitidez visual y detalle. La instantánea es "un punto que no se presta a la descripcion o a la lectura: ni tiene la extensión suficiente para permitir un recorido visual, ni el gorsor suficientepara engendrar una narración" (De Duve, 2013, p. 73). De este modo, la fotografía instantánea se revelaría como una imagen no narrativa antes que estrictamente en estasis. En cambio, el posado está envuelto por la estética de un halo borroso, de un matizado desefonque, resultante de la escasa profundidad de campo o de deficiciencias ópticas de la lente -citemos el caso de los retratos de Julia Margaret Cameron o las fotografías de los pictorialistas-4, y

\footnotetext{
4 Junto al retrato De Duve cita el paisaje y la naturaleza muerta como temáticas propias del posado en su dimensión narrativa. A este respecto es posible sugerir la interpretación de estos temas bajo lo que Michael Fried llamó escenas "absortivas" (naturaleza muerta y ciertos tipos de paisaje y retrato) vinculadas a toda una tradición de la pintura occidental de corte realista desde Caravaggio a Courbet. Según el crítico formalista, el tema absortivo es de carácter durativo porque en lo representado se da un efecto de permanencia, de reiteración como si el instante representado se extendiese siempre igual a sí mismo (Fried, 1988). La noción de absorción es posteriormente retomada en su aplicación a la fotografía contemporánea y en particular en el
} 
aún amenzado por una "afasia momentánea", su función es consoladora -como la del duelo- y su vocación proustiana: "en la circulación de la mirada es lo que se fundamenta el tiempo del posado, que hay que entender como una pausa de tiempo, cargada de un potencial de actualización que realiza la palabra o el recuerdo como palabra interiror" (De Duve, 2013, p. 77). La fotografía de

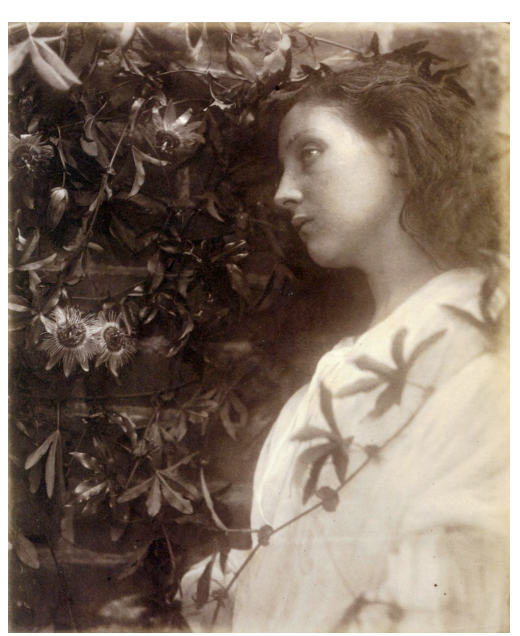
posado se constituiría, por tanto, como no sometida por completo a la estasis más que como una imagen narrativa propiamente dicha. De este modo, bajo nuestro punto de vista cabe concluir que la paradoja interna de la fotografía se articularía de modo más adecuado sobre la polaridad entre términos negativos - no narrativa vs. no estática- que asertivos -narrativa vs. estática-.

F1. Julia Margaret Cameron, Maud, 1875

\section{Derivaciones de la paradoja fotográfica}

De este planteamiento se deprenden dos ideas entrelazadas que resultan centrales a la hora de analizar la relaciones entre tiempo y narratividad en la fotografía, y que a la postre apuntan hacia una matización de los caracteres fenomenológicos y estéticos en los que se articula su paradoja interna. La primera se refiere al hecho de que la construcción narrativa de las imágenes es un fenómeno inferido o construido por una cierta mirada perceptiva del espectador5. La posibilidad diegética de una imagen inmóvil, gracias a su conformación icónica y compositiva interna, puede excitar una actividad perceptiva más cinemática que contemplativa, impelida a desplegar el recorrido de la mirada como diégesis visual, tanto superficialmente -sobre la cualidades plásticas de la imagne- como en profundidad -sobre un tercer eje diacrónico de

análisis de la obra de Jeff Wall (Fried, 2009, p. 37 y ss.). Un análisis detallado de las ideas del crítico norteamericano sobre el tiempo en el arte moderno se encuentra en Díaz (2011).

5 Para profundizar en la importancia de los procesos de lectura de las imágenes por parte del espectador consultar Baetens, Streitberger \& Van Gelder (2010). En el contexto analítico de las imágenes fijas, el manejo del concepto de narratividad tiene un sentido analógico en tanto que funciona como correlato de la experiencia fenomenológica del perceptor. 
tiempo sostenido-, sin quedar atascada en la sorpresa paralizante del detalle absoluto de la instantáena. Es como si el corte seco del tiempo de exposición en el momento de la toma se dilatise en el acto de su percepción como imagen. Para De Duve el tiempo de la instantáena actúa como un punto de fuga imaginario: desde el antes del tiempo referencial al aquí del espacio representado. Mientras, en el posado, el tiempo aparece extendido, un tiempo de continuidad en el que todas las flexiones son posibles y, por tanto, ya sea a través del recuerdo o de la palabra, pueden ser narradas o al menos evocadas. En ambos casos se trata de un tiempo puramente fenomenológico, de una temporalidad experimentada en el acto de percepción, que no hay que confundir con la duración real de la contemplación de la imagen. Nos hallamos cerca de lo que Michael Fried, a propósito de sus análisis de la pintura abstracta de Jules Olitski, llamó la experiencia de un "tiempo visual” de la obra, un tiempo entendido en términos de duración que hace referencia a la forma de percpeción sucesiva de los elementos compositivos -cromáticos en este caso- del cuadro (Fried, 1998, pp. 247-250). De este modo, la inteligibilidad narrativa queda atada a la experiencia perceptiva de la imagen y su empatía con el espectador6. Si Barthes consideraba que el punctum era una "especie de sutil más-allá-delcampo, como si la imagen lanzase el deseo más allá de lo que ella misma muestra" (Barthes, 1990, p. 109), el pensador belga parece sugerir un similiar anhelo a través de un, igualmente sutil, más-allá-del-tiempo representado7.

\footnotetext{
${ }^{6} \mathrm{El}$ reverso del tiempo perceptivo se podría encontrar en la temporalidad del propio proceso de producción fotográfica -casi siempre obviada en los escritos teóricos sobre fotografía-. No es el la duración del tiempo cronológico sino su vivencia subjetiva por parte del fotógrafo. Un tiempo que, como apunta el crítico Santiago Olmo a propósito de los trabajos documentales de Adriana Lestido o Miguel Río Branco, es compartido emocionalmente hablando entre el fotógrafos y los sujetos fotografiados y que funcionaría como sostén del sentido narrativo del proyecto documental (Olmo, 2010).

7 Podemos acercar este "más-allá-del-tiempo" al planteamiento que Eduardo Cadava (2001 y 2010) lleva a cabo, desde la perspectiva de la filosofía de Walter Benjamin y su concepto alegórico de "ruina", al poner en relación la representación del tiempo en la fotografía y la posibilidad de su lectura con la comprensión dialéctica -no lineal y crítica- de la historia. Dando un paso adelante en la estela del pensamiento benjaminiano, el porfesor Ulrich Baer propone el carácter esencialmente performativo de la fotografía en tanto que nos dirige hacia un tiempo que está abierto a transformación, resituándonos en la historia "con más conciencia, más plenitud y más vida" (Baer, 2010, p. 51). En ambos casos, el concepto benjaminiano del tiempo en la fotografía como interrupción y vacío entre el pasado y el futuro se concibe conectada con la construcción de la conciencia histórica y su narrativa que el filósfo alemán desarrolla en sus "Tesis de filosofía de la historia" (Benjamin, 1989).
} 
En segundo lugar, De Duve en su ensayo engarza de modo explícito la modulación de la función diegética con el componente estético de la imagen fotográfica. Si bien es cierto que asume como punto de partida la naturaleza indicial de la imagen fotográfica, en tanto que es la marca semiótica que la define de modo radical frente a las demás artes plásticas y lo que determina su particular constitución sígnica, no parece entregado -al menos completamentea la idea de la especificidad estética del medio fotográfico. Cuando en 1966 John Szarkowski, a la sazón director del Departamento de Fotografía del MoMA, en sintonía con el paradigma greenbergiano de la modernidad artística (Greenberg, 2006) ${ }^{8}$, detalla los rasgos que conforman la identidad estética de la fotografía y su particular sintaxis visual (la cosa misma, el detalle, el encuadre el tiempo y el punto de vista) viene a incidir en el déficit narrativo de la fotografía como uno de su rasgos específicos (Szarkowski, 2010, pp. 8 y 10). No cabe duda de que, hasta cierto punto, De Duve podría compartir esta afirmación, especialmente cuando se refiere a la fotografía instantánea pura -la fotografía de prensa y la científica-. Sin embargo, no es menos cierto que maneja la idea de que las cualidades estéticas son catalizadoras de una competencia narrativa de las imágenes fotográficas no sólo en el posado sino también en la instantánea, relativizando la tensión entre las respectivas fórmulas estéticas del detalle instantánea- y del halo borroso -posado-. De este modo, reconoce el papel del factor estético-formal presente en el instante decisivo de Henri Cartier-Bresson, surgido de la óptima adecuación entre contenido y la estructura compositiva de la imagen en el preciso instante en que culmina la acción. El efecto inmediato de esta cualidad estética es atenuar el trauma de la instantánea tornándolo significante para el espectador, quien ya no quedaría noqueado y mudo e imprimiría a la instantánea “una diégesis potencial” (De Duve, 2013, pp. 74-75).

\footnotetext{
8 El tratamiento de la especificidad del la fotografía como medio artístico desde la perspectiva del formalismo moderno, no corresponde realmente a Clement Greenberg más allá del papel inspirador de sus tesis sobre la pintura moderna. El principio normativo de "exclusión del tiempo" en la pintura y la noción de la obra como "espacio puramente óptico" dificultan el encaje de sus posiciones estéticas con la fotografía. Ha sido Michael Fried, discípulo a la vez que crítico de aquel, quien ha desarrollado la cuestión de la especificidad del medio fotográfico enfocándola desde la perspectiva de sus posiciones teóricas sobre la pintura (Fried, 2008), partiendo de conceptos críticos ya presentes en textos seminales de los años 60 como "Shape as Form: Frank Stella's New Paintings" de 1966 y “Art and Objecthood” de 1967 (Fried, 1998). Para un discusión en profundidad sobre la cuestión de la especificidad medial de la fotografía en el crítico norteamericano se puede ver el artículo de Costello (2008).
} 


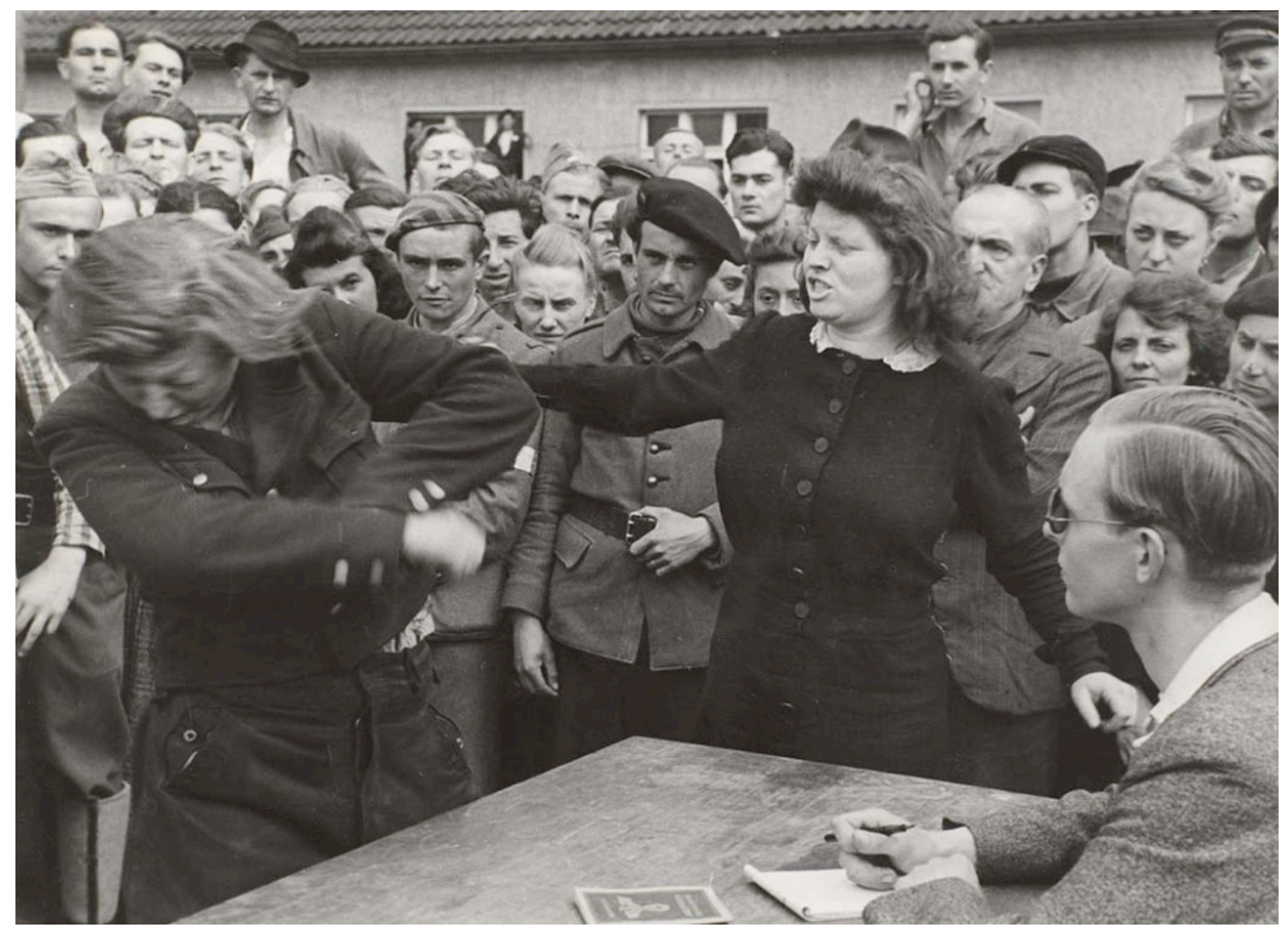

F2. Henri Cartier-Bresson, Dassau, Alemania, 1945

El crítico de cine Guy Gauthier ha apuntado cómo en las instantáneas del fotoperiodismo más audaz la suspensión del tiempo y de la acción no deja la “posibilidad de construir un relato tranquilizador, regulador de tensión" porque "la verdadera instantánea se limita a estirar el instante como idéntico a sí mismo (...) indefinidamente en suspenso” (Gauthier, 1996, p. 89)99. Para el crítico francés sólo cabe un único desenlace o continuación para esa imagen: otra imagen que le suceda en la secuencia de los acontecimientos. Esto es precisamente lo que no ocurre con una instantánea de momento decisivo: se basta a sí misma para transcenderse en su significación temporal. Aquí subyace la idea, inspirada en el ilustrado alemán Lessing, y recogida en el texto de Thierry de Duve, de que las artes visuales, en tanto que artes del espacio, están

\footnotetext{
${ }^{9}$ A propósito de esta mención a la fotografía periodística, y como complemento al análisis de Gautheir, es oportuno señalar el hecho de que las imágenes fotoperiodísticas -y otras como las publicitarias- sirven generalmente como ilustradoras de la codificación escrita, de acuerdo con las funciones de anclaje y relevo de las que habla Barthes (1995b) en relación a cuál sea el código dominante.
} 
sometidas al empleo de elementos yuxtapuestos de modo simultáneo y que por tanto deben extraer de la transitoriedad de momentos aquel instante "más pregante" que mejor represente la esencia del acontecimieto. De esta manera, el espectador será capaz por sí mismo de prolongar con su imaginación una acción que no se agota en lo presentado y que "permita hacerse cargo lo mejor posible del momento que precede y del que sigue” (Lessing, 1977, p. 166), esto es, que posibilite que una narración pueda ser evocada ${ }^{10}$. Mientras que en las artes plásticas es evidente la naturaleza estética -escenificación codificada de gestos y posturas- del instante esencial que no se corresponde con ninguna realidad fisiológica (Aumont, 1992, p. 245), en el caso del momento decisivo concebido por Cartier-Bresson la cualidad estética reside en el orden compositivo interno como expresión de un efectivo acmé de la acción que acontece en la realidad y que la cámara fotográfica registra sin violentar la credibilidad de nuestra percepción, a diferencia de aquellas posturas inverosímeles sin equivalente perceptivo que ofrece la instantánea del momento cualquiera del galope de un caballo ${ }^{11}$.

Como contrapunto a esta lectura esteticista del instante decisivo, el teórico del arte Jean-Marie Schaeffer ha mostrado cómo, lo que en principio es una definición meramente técnica del registro de la fugacidad temporal, ha terminado por desembocar en una definición que contiene "una verdadera ontología temporal” de la imagen fotográfica: su capacidad para retener en

\footnotetext{
${ }^{10}$ En Laocoonte, o sobre las fronteras de la poesía y la pintura, de 1776, Lessing distingue entre las artes del tiempo que como las artes literarias, y particularmente la poesía, emplean elementos - palabras- que se disponen según un orden sucesivo en el tiempo, y las artes del espacio, como la pintura por ejemplo, que utilizan "partes yuxtapuestas" que se disponen simultáneamente en el espacio (Lessing, 1977, pp. 165-166). En la segunda mitad del siglo XIX, los teóricos formalistas Konrad Fiedler y Adolf Hildebrand continuaron con la distinción entre la pintura y la escultura, concebidas como artes de "pura visualidad", frente a la música y la literatura como artes del tiempo. Si estas ultimas hacen uso de recursos narrativos para la representación de acciones que se desarrollan en el curso del tiempo, las artes visuales atienden a la espacialidad -en tanto que asociada a lo puramente visual- sin cabida para lo relacionado con el tiempo y lo sucesivo (Fiedler, 1990 y Hildebrand, 1989). En cierto modo, esta contraposición irreconciliable entre las artes del espacio y las del tiempo se efectúa en los términos de la paradoja fotográfica en tanto que por su génesis automática, a diferencia del resto de las artes visuales, lleva inscrita la huella material del tiempo en su superficie espacial. Una articulación entre espacio y tiempo que según De Duve tiene lugar, de acuerdo con lo analizado, mediante una sucesión de conmutaciones quiasmáticas entre el aquí-antes de la instantánea y el ahora-allí del posado (De Duve, 2013, p. 71).

${ }^{11}$ John Szarkowski, por el contrario, de acuerdo con su criterio sobre la sintaxis visual de la fotografía, pensaba que "lo que tiene lugar en el momento decisivo no es un clímax dramático sino visual. El resultado no es una historia sino una imagen” (Szarkowski, 2010, p. 10).
} 
presente la esencia del tiempo condensado "en instantes decisivos de significación eterna” (Schaeffer, 1990, p. 138). Una ontología esencialista que respalda una concepción estético-simbólica de la imagen fotográfica a la vez que sirve como coartada para una "estrategia receptiva transitiva" en la que la imagen se utiliza con fines comunicacionales trascendentes casi siempre conformados en términos diegéticos. Un planteamiento estético-fotográfico en el que subyace una "violencia” inscrita en el mismo acto hermenéutico que más que enriquecer la lectura de la imagen la imposta. En opinión del filósofo francés, el verdadero significado de la imagen fotográfica reside en otras de sus cualidades o condiciones que no son precisamente de carácter estético o simbólico, sino la contingencia y la precariedad fundadas en su constitución como signo indicial. La fotografía, así, aniquila el relato -su verbalización mediatizada por la cultura icónica- en favor de la "emoción perceptiva” del instante, éste es su único y específico efecto esético (Schaeffer, 1990, p. 148). Este rescoldo irracional de lo fotográfico, que tanto recuerda al punctum barthesiano, surge de la proximidad de una experiencia privada de la imagen que anula la "distancia semiótica" necesaria para que la fotografía, a diferencia de lo que sucede en la pintura, adquiera un espesor cultural y estético propios (Schaeffer, 1990, p. 152). El modo de significar de la fotografía no descansa en la promesa hermenéutica de una verdad por revelar - a lo Edward Weston- o de una ampliación de nuestra experiencia perceptiva - a lo Moholy-Nagy-, sino que "se conforma con ser por lo que se da", en ser "una imagen donde hay que ver pero nada -o poco- que decir" (Schaeffer, 1990, p. 156). Y éste no ser más que una imagen -esta extrema superficialidad semántica- es lo que, a su juicio, ha provocado que "la entrada de la fotografía en los arcanos del arte haya agrietado la perfecta estructura del pensamiento estético" (Schaeffer, 1990, p. 115).

\section{Más allá de la paradoja: la expansión de lo fotográfico}

La contraposición entre instantánea y posado que enuncia la paradoja interna de la fotografía la hemos analizado en correlación con la estasis y la narración, apuntando, de acuerdo con Thierry de Duve, el papel de factores internos -o 
estético-formales- y fenomenológicos -o perceptivos- en la conformación de la dimensión narrativa de la imagen fotográfica. En todo momento el análisis se ha mantenido dentro de los márgenes de la fotografía en tanto que imagen fija y aislada, ceñida a las condiciones de su especificidad -técnica y sígnica- como medio visual moderno, en el sentido greenbergiano de la expresión. Sin embargo, bajo el estímulo posmoderno de las últimas décadas del siglo XX y lo que se etiquetó como hibridación medial (Crimp, 2001), toda una serie de prácticas artísticas dieron lugar a transformaciones estéticas imbricadas con la imposición de una lógica de lo fotográfico (Krauss, 1996a) y, por tanto, asociadas con la indicialidad, la fragmentación, la reproductibilidad e inserción en los mass media, la copia y la disolución de la autoría. Sobre la fotografía se dejaba sentir el peso de sus usos sociales y el papel de mecanismos textuales, contextuales y discursivos en la construcción de su significado ${ }^{12}$. Se podría decir que el resto de las artes visuales se tornaron fotográficas. La organización de las imágenes en series o en secuencias, el recurso a los conceptos de archivo y de tipología o la adopción del montaje y la escenificación (directorial mode) constituyeron estrategias de producción artística que abonaban el desarrollo de la dimensión narrativa de la imagen, desbordando las constricciones estéticas de la oposición entre instantánea y posado pero dando, no obstante, una nueva lectura al juego entre estasis y narratividad. En esta línea, podemos señalar las secuencias fotográficas de Duane Michals y Sophie Calle; la revisión crítica del concepto de documento planteado por Martha Rosler a mediados de los años setenta en "The Bowery en dos sistema descriptivos inadecuados", donde la serie fotográfica se estructura sobre la alternancia entre imagen y texto; o las fotocomposiciones de estructura secuencial realizados por el artista conceptual John Baldessari a partir de fotogramas apropiados de producciones cinematográficas de serie B. Los fotomontajes de texto e imagen con una potente carga social de Barbara Kruger, diseñados para su ubicación pública en vallas publicitarias o para ser impresos en objetos de uso como bolsas de compra o camisetas, y las escenificaciones fotográficas de autores como Sandy

\footnotetext{
$12 \mathrm{El}$ argumento central de los estudios sobre la fotografía en la posmodernidad ha sido cuestionar la idea de una identidad estética esencial de la fotografía como arte y analizar la fotografía como medio sometido a aplicaciones utilitarias diversas en relación con la cuales juega un específico papel ideológico y cultural, (Squiers, 1990; Younger, 1991; Ribalta, 2004).
} 
Skoglund o Bernard Faucon en las que lo onírico, la mitología personal y lo literario son las claves de su significado diegético ${ }^{13}$, completan un conjunto de referencias artísticas de inclinación narrativa. Incluso el work-in-progress de Bern y Hilla Becher sobre arqueología industrial, donde la serialización fotográfica de tipologías constructivas es la base de su producción artística, nos pondría en la pista de cómo la fijación mediante la fotografía de motivos repetitivos es capaz de inervar, a través del concepto de archivo documental, una operación de conciencia histórica -durativa-y, por tanto, un cierto sentido narrativo ${ }^{14}$.

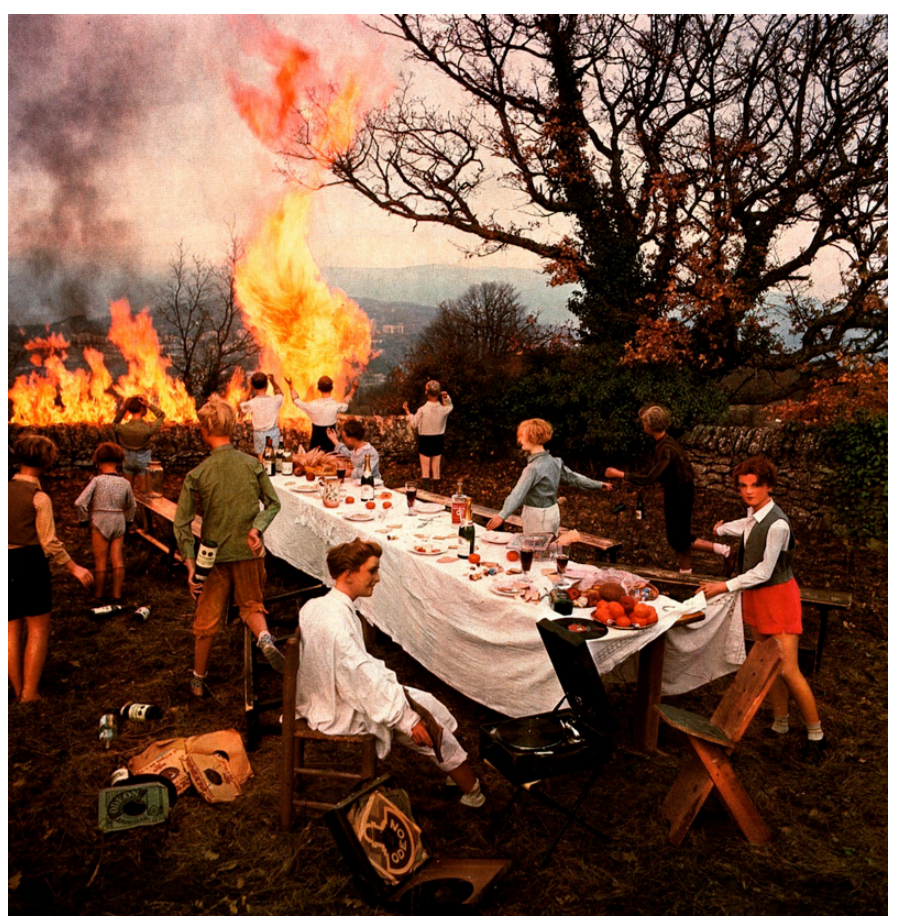

F3. Bernard Faucon, El banquete, 1978

Por otra parte, si dichas producciones posmodernas podrían ser descritas y teorizadas como fotográficas, la infiltración de lo digital -y su extensión en las funcionalidades de la web 2.0- ha provocado que las nuevas formas del arte contemporáneo y sus realizaciones icónico-fotográficas se acerquen más a lo

13 En relación con esta cuestión François Brunet (2009, p. 149) analiza cómo a partir de los años setenta la fotografía artística incorpora, con las escenificaciones, un componente teatral que es promotor esencial de su dimensión ficcional, y por tanto narrativa, que posibilita una nueva lectura de las relaciones entre fotografía y literatura.

${ }^{14}$ El ensayo de George Baker (1996) sobre August Sander y su producción de retratos antecesora estética del planteamiento de los Becher- apuntaría en este mismo sentido. 
cinemático, y por tanto a lo diegético, que a lo propiamente fotográfico o estático (Campany, 2007), tanto más cuanto el paradigma técnico y estético de la fotografía tradicional ha sufrido una profunda ampliación que George Baker ha bosquejado como "campo expandido de la fotografía" (Baker, 2008), de acuerdo con el patrón crítico que Rosalind Krauss planteara a principios de los años ochenta como análisis de los cambios producidos en la noción de escultura (Krauss, 1996b). En este sentido, la imagen fotográfica contemporánea, en su trabazón entre estasis y narración, es cada vez más una imagen reconstruida en un sentido amplio ya que su impulso intermedial ha trasformado lo que queda de eso que llamamos fotografía. Por un lado, podemos distinguir una imagen reconstruida mediante nuevas estrategias de puesta en escena de un claro referente cinematográfico. Philip-Lorca diCorcia en cada una de sus fotografías de ambiente callejero apuesta por una clara dramatización de personajes y elementos escenográficos -con un especial control sobre la iluminación-, al servicio de una narrativa que puede llegar a bordear los límites de lo documental, como en la serie sobre gigolós de la ciudad de Los Ángeles. Por su parte, la australiana Tracy Moffat articula su personal relato en secuencias fotográficas a partir de escenografías construidas en el estudio. En ambos casos, se trata de producciones fotográficas, en general, bastante cercanas al concepto de film still, tal como se muestra en los primeros trabajos de Cindy Sherman donde la componente performativa no es un factor secundario.

En otros planteamientos se reconoce esta misma vena cinematográfica pero reforzada mediante la aplicación del dispositivo digital. Gregory Crewdson realiza fotografías de una radical transparencia que representan momentos que han sido construidos -acabados- en el proceso de posproducción digital a partir de varias tomas fotográficas de una misma escena. Sus fotografías condensan realidad y ficción en una diegética indefinida pero compulsiva, según sus propias palabras son como una "ecuación irresuelta" (Crewdson, 2008). 


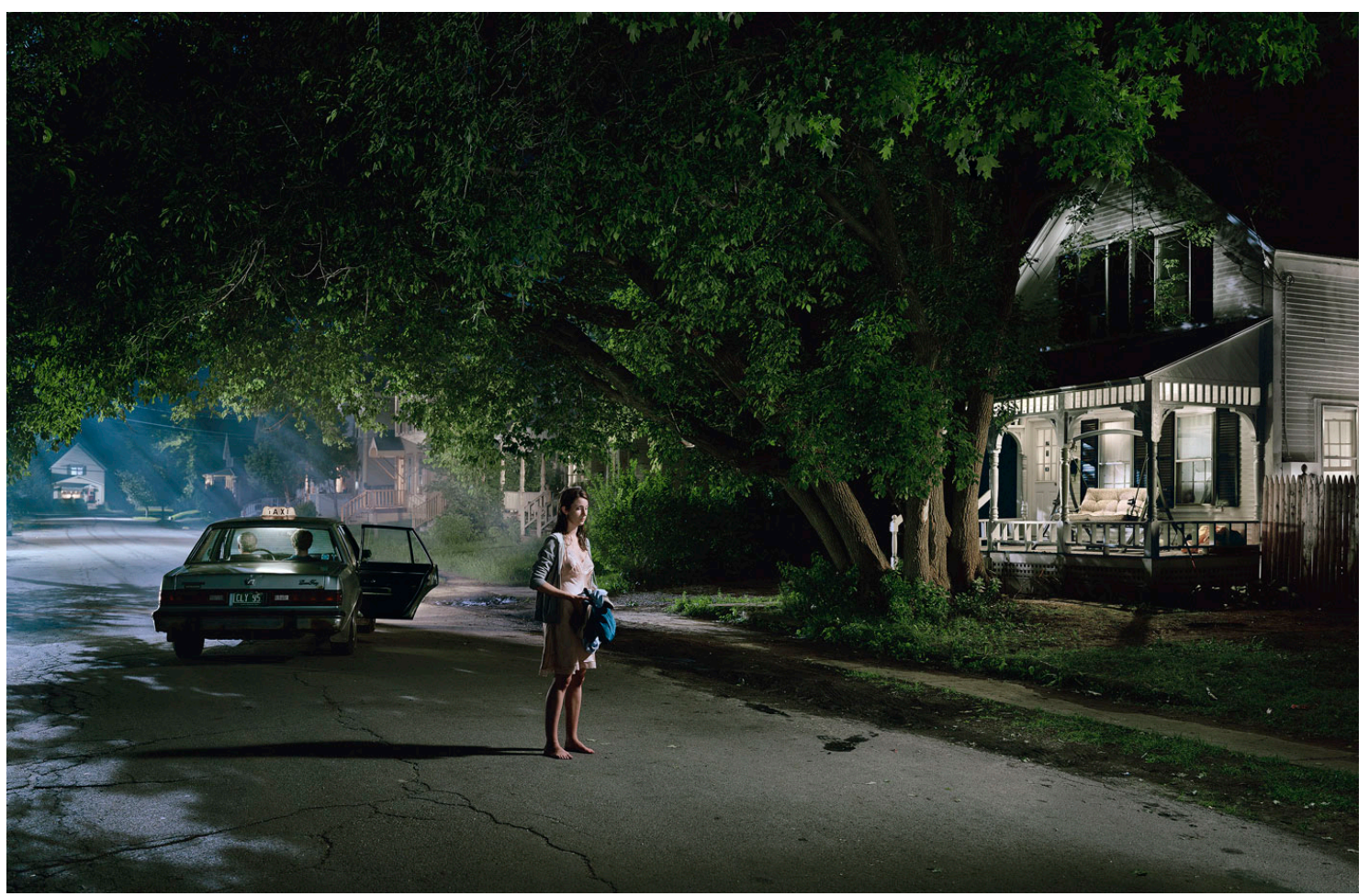

F4. Gregory Crewdson, Maple Street, 2010

Jeff Wall ha llevado a cabo esta reconstrucción de la fotografía utilizando la clave intertextual de la tradición pictórica realista, para crear un efecto cinematográfico y una apariencia orgánica de la representación gracias al uso de retoque digital. El propio artista canadiense afirma que la fotografía vive gracias al intervalo infinitamente matizado entre el modo documental y el cinematográfico (Camapany, 2014, p. 62). El dispositivo del ordenador, de acuerdo con el análisis de José Luis Brea (1996), actuaría como "un segundo obturador" que no congela el tiempo sino que lo convierte en un "tiempomovimiento", en un "instante-devenir" implícito que se despliega en el tiempo expandido de la lectura de la imagen. Como muestran las escenificaciones y fotomontajes del artista canadiense, el resultado es una cinematización interna de la imagen que desliza su significado hacia la narración y lo cinematográfico "con el potencial simbólico que le otorga toda su fuerza para instituir mundos" (Brea, 1996, p. 45). Como último ejemplo dentro de esta línea de intervención digital queremos citar la obra de la norteamericana Nancy Davenport y su obra Weekend Campus de 2004 -un homenaje a la película Week-end (Jean-Luc Godard, 1967) y su conocida secuencia del accidente de tráfico- en la que la 
imagen fotográfica, funcionando como una auténtica muestra de still moving, no permanece estática sino que se presenta con un desplazamiento lento. A través de la escena fotografiada -compuesta digitalmente mediante una sutura continua de diferentes registros- se suceden coches siniestrados, estudiantes, profesores y policías presentes en accidentes de tráfico que han tenido lugar a la entrada de un campus universitario. En esta obra realizada en formato DVD, objetos y personas permanecen estáticos e inmóviles -excepto el destello de las luces de los coches patrulla de la policía-, congelados por la cámara tras los accidentes. Simultáneamente todo sucede y todo ha sucedido dentro de una secuencia en bucle, creando una ilusión de continuidad temporal, como de momento histórico suspendido sin fin en el tiempo (Davenport, 2008).

\section{De la fotografía al cine y viceversa}

Junto al proceso de digitalización que ha fortalecido la idea de una imagen fotográfica de carácter cinemático, es importante tener en cuenta también la enriquecedora profundización en las relaciones entre cine y fotografía que en estos últimos años ha sido objeto de reflexión teórica e investigación histórica (Campany, 2007; Beckman \& Ma, 2008; Guido \& Lugon, 2012; Mira, 2013). De manera paralela a la articulación de estas específicas formas de narratividad de la fotografía y de recomposición de su paradoja interna, ciertas prácticas cinematográficas han venido a incidir, desde hace años, sobre la esencia inmóvil o fotográfica de la diégesis narrativa del cine. En este sentido, las relaciones entre el cine y la fotografía han sido complejas y no exentas de tensiones en la medida que las cualidades técnicas y estéticas de uno se han visto codiciadas y adoptadas por el otro, en una mezcla de códigos que incluso ha trascendido la estricta dualidad medial implicando al vídeo, la pintura y las artes escénicas. Como ha apuntado Philippe Dubois, se exige que el análisis de estas relaciones sea oblicuo y transversal, "imaginando a uno iluminado por el otro, a uno a través del otro, en el otro, por el otro o como otro" (Dubois, 1995, p. 152). Mediante la incorporación de recursos como el montaje o las series, la fotografía ha ahondado en su dimensión temporal; con la explícita integración del 
fotograma y la fotografía filmada, el cine ha convertido la inmovilidad en motivo estético y metodología de reflexión.

En los años sesenta y setenta surge un cine experimental que también participó de un interés por la inmovilidad y la lentitud guiado por una vocación autorreflexiva, de interrogación sobre el propio funcionamiento del cine como lenguaje y/o como dispositivo de visión y percepción, con ejemplos paradigmáticos como La Jetée (Chris Marker, 1962), Wavelength (Michel Snow, 1967) o Hapax Legomena I: Nostalgia (Hollis Frampton, 1971). Películas en las que la relación entre cine y fotografía aparece como algo inextricable, donde las imágenes fotográficas se inscriben con toda su ambigüedad, dotadas de una densa profundidad y, al mismo tiempo, de una superficialidad opaca e impenetrable. Hecho que prueba, como ha escrito Mary Ann Doane (2006, p. 67), que el cine, a pesar de tener su propia historia, se ha vuelto hacia la fotografía como generadora de "dilemas epistemológicos" capaces de contaminar la propia estructura temporal y narrativa cinematográfica.

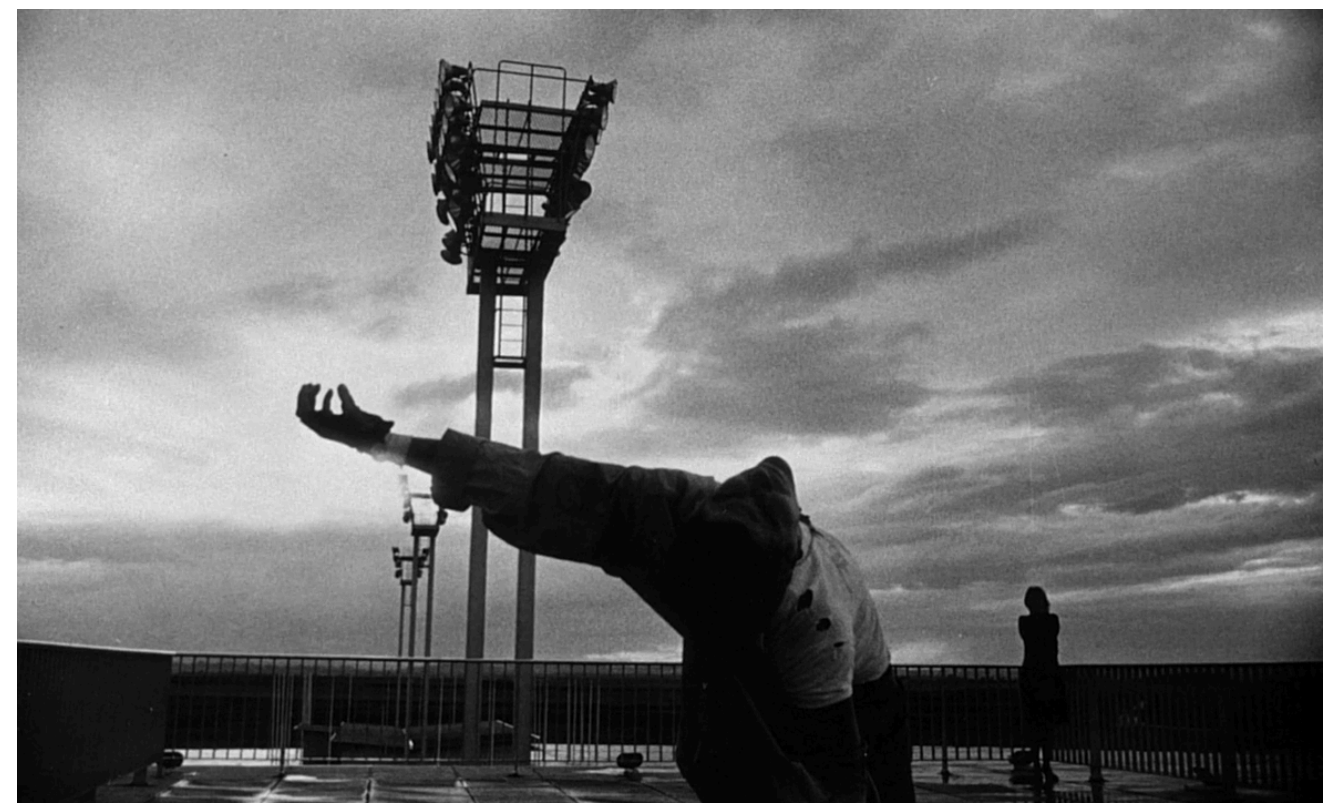

F5. Chris Marker, La jetée, 1962

En discusión con las reflexiones barthesianas sobre la fotografía, Raymond Bellour ha sido uno de los primeros teóricos en reflexionar sobre la captación de una película "a través del espectro de la fotografía" y cómo el tratamiento de 
lo inmóvil fotográfico mediante la inserción de imágenes congeladas, interrupciones del movimiento o gestos inmovilizados, modifican el sentido y el hilo de la historia narrada y, sobre todo, tiene el turbador efecto de despegar al espectador de la ficción cinematográfica y su flujo temporal tornándolo un "espectador pensativo" (Bellour, 2002; Mulvey, 2006). Roland Barthes nunca ocultó su escasa estima por el cine y las formas narrativas que someten al espectador a la irreversibilidad del vector del tiempo lineal, frente a su fascinación por la inmovilidad de la fotografía que permite otro modo de contemplación. Mientras la imagen cinematográfica es fugaz y nos lleva con ella en su fuga, la fotográfica nunca se deja asir por completo; mientras en el cine "no soy libre de cerrar los ojos" sometido a la voraz continuidad de una ilusión de vida, en la fotografía he de "cerrar los ojos" y dejar que el punctum llegue como una alucinación "hasta la conciencia afectiva" (Barthes, 1990, pp. 105, 197); mientras el cine impone su tiempo de lectura, en la fotografía este tiempo es prerrogativa del espectador. Así, para Barthes, la fotografía es esencialmente "pensativa" mientras el cine carece de esa "pensatividad" (1990, pp. 81, 105106) ${ }^{15}$.

\section{A modo de conclusión}

El análisis de De Duve ha mostrado los límites de la narratividad fotográfica atrapada en la paradoja de sus dos formas excluyentes de temporalidad, haciéndose necesario apuntar hacia a lo fotográfico en un sentido expandido que no sea reducible a la fotografía en su acepción convencional, aún cuando ésta sea en última instancia su alma y guardián. Más bien, hay que situar la esencia de lo fotográfico en un punto de intermedialidad y no exclusivamente de tensión paradójica. $\mathrm{Al}$ analizar las relaciones entre cine y fotografía, Raymond Bellour apuntaba la idea de que lo fotográfico existe en un lugar intermedio entre el movimiento y la estasis: "en el movimiento es lo que interrumpe, lo que paraliza; en la inmovilidad, tal vez muestra su relativa imposibilidad" (Bellour,

\footnotetext{
15 Esto justifica el interés del pensador francés por el fotograma -puesto de manifiesto en "El tercer sentido"- como esencia de "lo fílmico", como elemento aislado del flujo narrativo que "se ríe del tiempo lógico" y permite "una auténtica mutación de la lectura" que deja aflorar el "sentido obtuso" reprimido por el film (Barthes,1995c, p.67).
} 
2008, p. 253). Imposibilidad, habría que precisar, como estasis absoluta y, por tanto, como posibilidad de un modo de movimiento -o sentido- narrativo. La contraposición duveana entre posado e instantánea, ya entrañaba, según nuestra interpretación, esta forma de oposición acomodaticia entre dos términos entendidos en su carencia o deficiencia más que en su completud ontológica - no estático vs. no narrativo-. La estasis fotográfica se puede discernir con claridad frente a la movilidad cinematográfica -como el hielo del fuego, según la expresión de Peter Wollen (2007)-: una estructura secuencial y narrativa frente a otra puramente estática, y descriptiva. Sin embargo, cuando la estasis de lo fotográfico se confronta a su propia inmovilidad relativiza su parálisis narrativa. Ya sea como instantánea o como posado, mediante la puesta en escena o mediante la reconstrucción digital, lo fotográfico deriva hacia una constitución cinemática como resultado de la constatación de su "relativa imposibilidad" estática y su prolongación en un tiempo fenomenológico, sostenido tanto por la experiencia perceptiva -durativa y pensativa- del espectador como por las estrategias de representación fotográfica y sus temas. La dimensión expandida y narrativa de lo fotográfico hallaría así su correspondencia en la producción de su propio tiempo interno: un "tiempo expandido" que "está potencial e indefinidamente lleno y vacío de todo los tiempos posibles" (Mah, 2010, p. 16).

\section{Referencias bibliográficas}

Aumont, J. (1992). La imagen. Barcelona: Paidós.

Baer, U. (2010). La suspensión del tiempo del obturador: hacia una teoría democriteana de la fotografía. En AA.VV. El tiempo expandido (pp. 4351). Madrid: La Fábrica.

Baetens, J., Streitberger, A. \& Van Gelder, H. (2010). Time and Photography, Lovaina: Leuven Unversity Press.

Baker, G. (1996). Photography between Narrativity and Stasis: August Sander, Degeneration, and Decay of Portrait. October, Vol. 76, 72-113.

Baker, G. (2008). Photograpy's Expanded Field. En Beckman, K. \& Ma, J. (Eds.), Stillmoving. Between Cienema and Photography (175-188). Durham: Duke University Press.

Barthes, R. (1990). La cámara lúcida. Barcelona: Paidós. 
Barthes, R. (1995a). El mensaje fotográfico. En Barthes, R. Lo obvio y lo obtuso. Imágenes, gestos, voces (pp. 11-28). Barcelona: Paidós.

Barthes, R. (1995b). Retórica de la imagen. En Barthes, R. Lo obvio y lo obtuso. Imágenes, gestos, voces (pp. 28-48). Barcelona: Paidós.

Barthes, R. (1995c). El tercer sentido. En Barthes, R. Lo obvio y lo obtuso. Imágenes, gestos, voces (pp. 49-67). Barcelona: Paidós.

Beckman, K. \& Ma, J. (Eds.) (2008). Stillmoving. Between Cienema and Photography. Durham: Duke University Press.

Bellour, R. (2002). Le spectateur pensif. En Bellour, R. L’Entre-Images. Photo, cinéma, vidéo (75-80). París: La Différence.

Bellour, R. (2010). La interrupción, el instante. En AA.VV. El tiempo expandido (pp. 109-134). Madrid: La Fábrica.

Benjamin, W. (1989). Tesis de filosofía de la historia. En Benjamin, W. Discursos interrumpidos I (177-191). Madrid: Taurus.

Brea, J. L. (1996). El inconsciente óptico y el segundo obturador (la fotografía en la era de su computarización). En Brea, J.L. Un ruido secreto. El arte en la era póstuma de la cultura (29-45). Murcia: Mestizo.

Brunet, F. (2009). Photography and Literature. Londres: Reaktion Books.

Cadava, E. (2001). “Lapsus Imaginis”: the Image in Ruins. October, Vol. 96, 3560.

Cadava, E. (2010). La imagen: un monstruo del tiempo. En AA.VV. El tiempo expandido (pp. 27-33). Madrid: La Fábrica.

Campany, D. (2014). Entrevista a Jeff Wall. Concreta. Sobre creación y teoría de la imagen, $\mathrm{n}^{\mathrm{O}} 4,54-63$.

Campany, D. (Ed.) (2007). The cinematic. Londres y Cambridge (MA): Whitechapel \& MIT.

Costello, D. (2008). On the Very Idea of a 'Specific' Medium: Michael Fried and Stanley Clavell on Painting and Photography as Arts. Critical Inquiry, Vol. 34, 274-312.

Crewdson, G. (2008). Interview with Gregory Crewson. Aperture. Vol. 190. http://www.aperture.org/crewdson/ [consulta en línea el 16 de noviembre de 2015].

Crimp, D. (2001). Imágenes. En Wallis, B. (Ed.), Arte después de la modernidad. Nuevos planteamientos en torno a la representación (175188). Madrid: Akal.

Davenport, N. (2008). Weekend Campus. En Beckman, K. \& Ma, J. (Eds.), Stillmoving. Between Cienema and Photography (189-195). Durham: Duke University Press.

De Duve, Th. (2013). El posado y la instantánea. La paradoja fotográfica. Concreta. Sobre creación y teoría de la imagen, $\mathrm{n}^{0}$ 2, 64-79. 
Díaz, D (2011). Cuestión de tiempo: Michael Fried y el tiempo del arte moderno. Aisthesis, $\mathrm{n}^{0} 49,29-52$.

Doane, M.A. (2010). Tiempo real: la instantaneidad y el imaginario fotográfico. En AA.VV. El tiempo expandido (pp. 61-79). Madrid: La Fábrica.

Dubois, Ph. (1995): Photography Mise-en-Film. Autobiographical (H)istories and Psychic Apparatuses. En Pietro, P. (Ed.), Fugitive Images. From Photography to Video (152-172). Indianapolis: Indiana University Press.

Fiedler, K. (1990). Escritos sobre arte. Madrid: Visor.

Frampton, H. (1971). Hapax Legomena I: Nostalgia. H. Frampton: USA.

Fried, M. (1988). Absorption and theatricality: painting and beholder in the age of Diderot. Chicago y Londres: The University of Chicago Press.

Fried, M. (1998). Art and objecthood : essays and reviews. Chicago y Londres: The University of Chicago Press.

Fried, M. (2008). Why Photography Matters as Art as Never Before. New Haven y Londres: Yale University Press.

Gauthier, G. (1996). Veinte lecciones sobre la imagen y el sentido. Madrid: Cátedra.

Greenberg, C. (2006). La pintura moderna. En Greenberg, C. La pintura moderna y otros ensayos (111-120). Madrid: Siruela.

Guido, L. \& Lugon, O. (Eds.) (2012). Between Moving and Still Images, New Barnet: John Libbey.

Hildebrandt, A. (1989). El problema de la forma en la obra de arte. Madrid: Visor.

Krauss, R. (1996a). Notas sobre el índice (Partes 1 y 2). En Krauss, R. La originalidad de la vanguardia y otros mitos modernos (209-235). Madrid: Alianza Editorial.

Krauss, R. (1996b). La escultura en el campo expandido. En Krauss, R. La originalidad de la vanguardia y otros mitos modernos (289-301). Madrid: Alianza Editorial.

Lessing, G.E. (1977). Laocoonte, o sobre las fronteras de la poesía y la pintura. Madrid: Editora Nacional.

Mah, S. (2010). El tiempo expandido. En AA.VV. El tiempo expandido (pp. 1319). Madrid: La Fábrica.

Marker, Ch. (1962). La Jetée. Francia: Argos Films.

Mira, E. (2013). Movilidad/inmovilidad: iluminaciones recíprocas entre cine y fotografía. Archivo de Arte Valenciano, Vol. XCIV, 321-341.

Mulvey, L. (2006). The pensive spectator. En Mulvey, L. Death $24 x$ a Second. Stillness and the Moving Image (181-196). Londres: Reaktion Books.

Olmo, S. (2010). El agente tiempo. En AA.VV. El tiempo expandido (pp. 229233). Madrid: La Fábrica. 
Ribalta, J. (Ed.) (2001). Efecto real. Debates posmodernos sobre la fotografía. Bercelona: Gustavo Gili.

Schaeffer, J.M. (1990). La imagen precaria. Madrid: Cátedra.

Snow, M. (1967). Wavelength. Coproducción Canadá-USA.

Squiers, C. (Ed.) (1990). The Critical Image. Essays on Contemporary Photography. Seattle: Bay Press,

Szarkowsky, J. (2010). El ojo del fotógrafo. Madrid: La Fábrica.

Wollen, P. (2007). Fire and Ice. En Campany, D. (Ed.): The Cinametic (108113). Londres y Cambridge (MA):

Younger, D.P. (Ed.) (1991). Multiple Views. Alburquerque: University of New Mexico.

Cómo citar: Mira Pastor, E. (2016). "Tiempo y narratividad en la fotografía; de la paradoja al campo expandido". Fotocinema. Revista científica de cine y fotografía, 12, pp. 61-80. Disponible: http://www.revistafotocinema.com/ 